\title{
Investigation of Thermal and Electrical Conductivity Properties of Carbon Black Coated Cotton Fabrics
}

\author{
Nergis D. GÜLTEKİN, İsmail USTA \\ Marmara University, Faculty of Technology, Department of Textile Engineering, Istanbul, Turkey
}

\begin{abstract}
In this study, the thermal and electrical conductivity properties of carbon black coated cotton fabrics were investigated. To obtain coated cotton fabrics, first carbon black nanoparticles were dispersed in distilled water. To improve dispersion stability of water based carbon black coating solutions, anionic wetting and dispersing agent was used. Plain weaved cotton fabrics were dipped into carbon black dispersion for 5 min. Because of the strong absorption, the cotton fabric was quickly coated by the carbon black dispersion. Then, the fabric with carbon black dispersion was subsequently dried in an oven at $120^{\circ} \mathrm{C}$ for $10 \mathrm{~min}$ to remove water. The dipping-drying process was repeated for 5 times to increase the carbon black loading in cotton fabric. Different carbon black concentrations on coating process were examined. The effects of carbon black loading on thermal and electrical conductivity properties of fabrics were investigated.
\end{abstract}

Keywords: Thermal conductivity, electrical conductivity, carbon black

\section{INTRODUCTION}

Design of functional and smart textiles is an area of great interest. Functionalization of textiles requires lightweight materials. The development of nanotechnology has stimulated research on applications of nanosized particles in textile processing [1]. There are different types of applications to employ nanoparticles in textiles. One of the possible applications is coating surfaces with the nanoparticles which can be dispersed well in coating solutions. Among the conductive fillers, carbon black has various advantages due to its low density, high surface area, good electrical conductivity, high chemical stability. Carbon black has a significant cost advantage over the highly conductive carbon materials like carbon nanotubes $[2,3]$. Carbon black nanoparticles are hydrophobic in nature and tend to aggregate in solutions. Therefore, hydrophilicity and dispersibility of the nanoparticles, which are the key to the nanoparticle coating of fabrics, should be increased [4]. Their most important properties for inks, coatings, and plastics are related to the final product appearance, UV protection, and electrical conductivity [5]. Carbon blacks have a conductivity in the range of 0.1 to $10 \mathrm{~S} / \mathrm{cm}$ at ambient temperature [6]. The electrical conductivity of carbon blacks depends on many parameters, such as their particle size (inversely proportional to the surface area), the aggregation of the carbon black particles (structure, measured as dibutyl phthalate absorption capacity) and the surface chemistry [7, 8]. But, besides their high electrical conductivity, carbon black fillers are relatively have low thermal conductivity according to the other carbon materials [9]. The thermal conductivity largely depends on aspect ratio and dispersion [10].

In this study, the thermal and electrical conductivity properties of carbon black coated cotton fabrics were investigated. To obtain coated cotton fabrics, first carbon black nanoparticles were dispersed in distilled water. To improve dispersion stability of water based carbon black coating solutions, anionic wetting and dispersing agent was used. Plain weaved cotton fabrics were dipped into carbon black dispersion for $5 \mathrm{~min}$. Because of the strong absorption, the cotton fabric was quickly coated by the carbon black dispersion. Then, the fabric with carbon black dispersion was subsequently dried in an oven at $120^{\circ} \mathrm{C}$ for $10 \mathrm{~min}$ to remove water. The dipping-drying process was repeated for 5 times to increase the carbon black loading in cotton fabric. Different carbon black concentrations on coating process were examined. The effects of carbon black loading on thermal and electrical conductivity properties of fabrics were investigated.

Corresponding Author: Nergis D. GULTEKIN, Tel: +90 21641405 45, E-mail: ndemirel@marmara.edu.tr Submitted: 15 October 2014, Revised: 04 March 2015, Accepted: 01 July 2015 


\section{EXPERIMENTAL}

\subsection{Materials}

Carbon black (CB) nanoparticles (Vulcan XC-72R, 10-20 $\mathrm{nm}$ in diameter) and dispersant (DELTA-DC 4242) were supplied by Cabot Corporation (USA) and Delta specialties WLL (Egypt), respectively. Both were used without any further treatment. DELTA- DC 4242 is an anionic wetting and dispersing agent for inorganic and organic pigments; and fillers in solvent-based, solvent-free and water-based systems. A plain weaved cotton fabric was used as matrix material, warp and weft densities are $30 \mathrm{warp} / \mathrm{cm}, 22 \mathrm{weft} /$ $\mathrm{cm}$, respectively. The basis weight of cotton fabrics is 113 $\mathrm{g} / \mathrm{m}^{2}$.

\subsection{Sample Preparation}

$10 \mathrm{mg} / \mathrm{ml}$ Delta-DC 4242 surfactant was dissolved in distilled water with the help of bath sonication. Then, carbon black nanoparticles were dispersed in the surfactant solution with $0.5,1,2$ and $5 \mathrm{mg} / \mathrm{ml}$ concentrations. After bath sonication for 10 minutes, probe sonication was used for 30 minutes to obtain well dispersed the carbon black dispersions. Plain weaved cotton fabric was dipped into the $\mathrm{CB}$ dispersion for 5 minutes, and then, the cotton fabric was removed and dried in an oven for 10 minutes. Coated cotton fabrics were weighed for measuring the particle uptakes by the fabrics. This process was repeated to increase the $\mathrm{CB}$ loading in the fabric.

\subsection{Characterization}

The morphology of the fabrics was investigated by scanning electron microscopy (SEM; JEOL Ltd, JSM-5910LV). Optical microscopy images of coated cotton fabrics were taken with Olympus SZ60 microscope. Volume resistivity measurements of $\mathrm{CB}$ coated cotton fabrics were tested using a two-probe method with Keithley 8009 Resistivity Test Fixture. The resistivity measurements of coated fabrics were tested at $1 \mathrm{~V}$. Volume resistivity is measured by applying a voltage potential across the specimen, measuring the resultant current and then performing the following calculation:

$\rho v=(22,9 / d) * R$

Where $\rho v$ is the volume resistivity of the specimen, $d$ is the thickness of the specimen $(\mathrm{cm}), \mathrm{R}$ is the resistivity $(\Omega)$ given by the instrument. The heat conduction apparatus was used to measure the thermal conductivity of the $\mathrm{CB}$ coated cotton fabrics according to the TS 4512 Standard.

\section{RESULTS AND DISCUSSION}

\subsection{Morphological Analyses}

Figure 1 shows the optical microscopy images of CB coated cotton fabrics. It is obvious from the images that the $\mathrm{CB}$ nanoparticles were coated on cotton fabrics successfully by dip coating method. However, coating process occurred on the surface of cotton fabrics and agglomeration of $\mathrm{CB}$ nanoparticles can be seen on fabric surface.

Figure 2 shows the SEM images of neat and different amount of $\mathrm{CB}$ coated cotton fabrics with different magnifications. It can be seen from the Figure 2(c, d) that the CB nanoparticles were coated on cotton fabrics no homogeneously, and also, agglomeration of nanoparticles can be seen. The images with $100 x$ of magnification of $0.5 \mathrm{mg} / \mathrm{ml} \mathrm{CB}$ reveal that the sample exhibits the lowest degree of CB agglomeration. Sample with $2 \mathrm{mg} / \mathrm{ml} \mathrm{CB}$ presents similar topological features, despite a slightly higher degree of aggregation. From the images with 500x of magnification, it is possible to observe that the CBs agglomerated on the surface of cotton fibres. The amount of dispersion absorbed of cotton fabric as a function of dipping numbers was given in Figure 3. It can be clearly seen that the increase in dipping numbers enhances the absorbed amount. The absorbed amount on cotton fabrics increases with the increase of $\mathrm{CB}$ concentration. When the $\mathrm{CB}$ amount was increased from $0.5 \mathrm{mg} / \mathrm{ml}$ to $2 \mathrm{mg} / \mathrm{ml}$, the coated CB amount reached its maximum value.
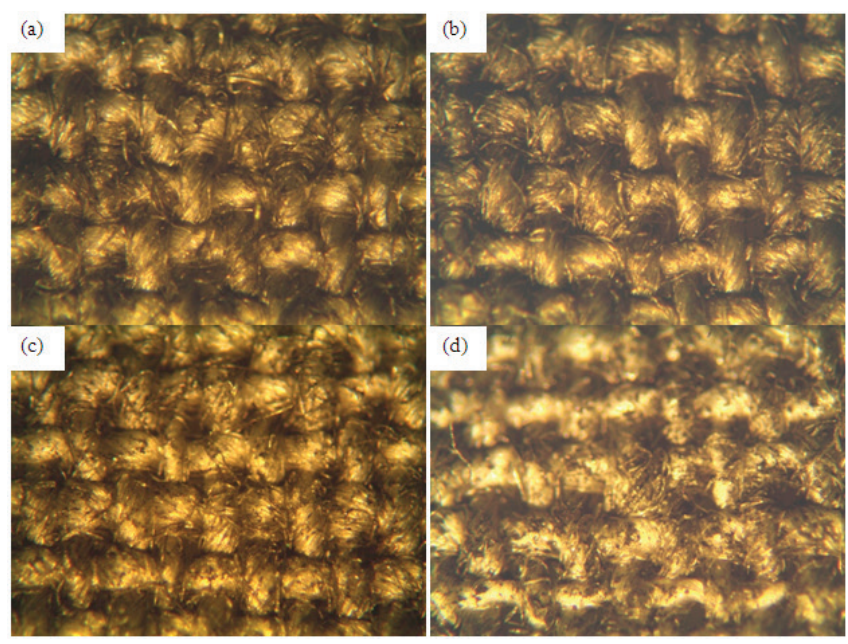

Figure 1. Optical microscopy images of $\mathrm{CB}$ coated cotton fabrics with different amount of CB loading; (a) $0.5 \mathrm{mg} / \mathrm{ml}$, (b) $1 \mathrm{mg} / \mathrm{ml}$, (c) $2 \mathrm{mg} / \mathrm{ml}$, (d) $5 \mathrm{mg} / \mathrm{ml}$ 

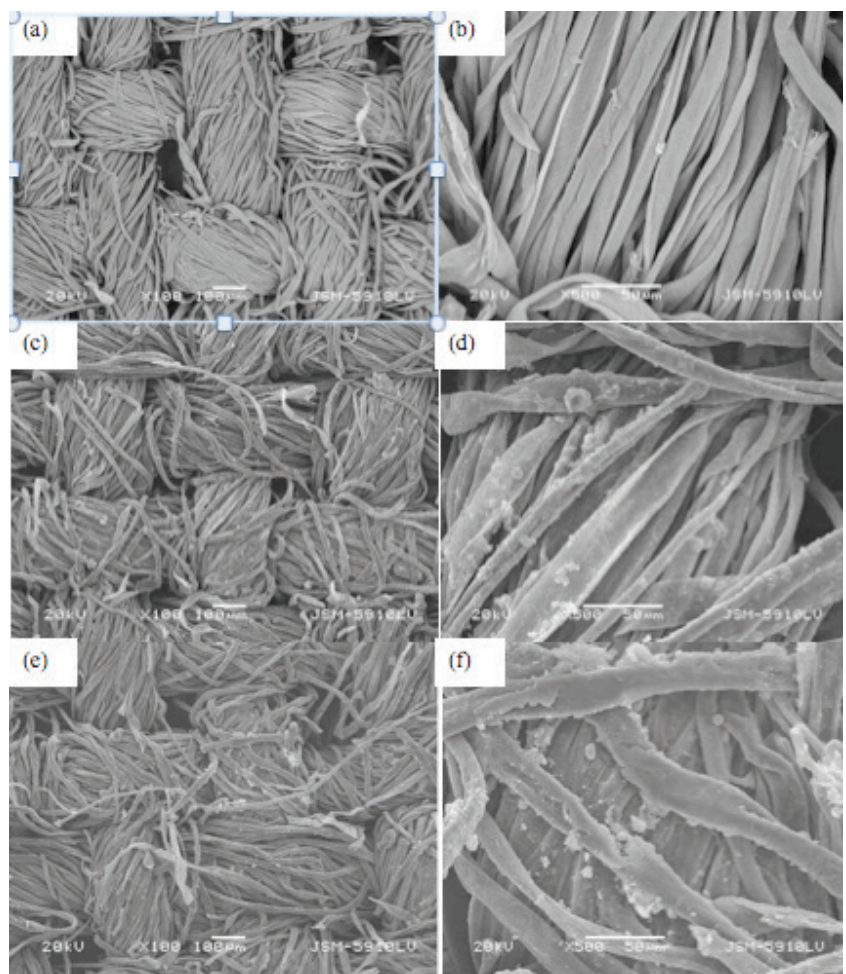

Figure 2. SEM images of $(a, b)$ neat cotton fabric, $(c, d) 0,5$ $\mathrm{mg} / \mathrm{ml}$ (e, f) $2 \mathrm{mg} / \mathrm{ml} \mathrm{CB}$ coated cotton fabrics.

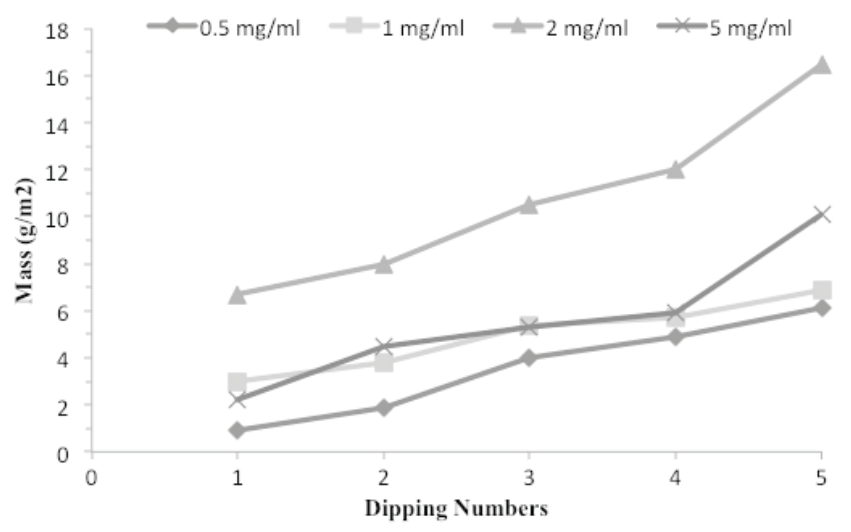

Figure 3. The amount of dispersion absorbed per area of cotton fabrics as a function of dipping numbers.

\subsection{Electrical Resistivity of Coated Fabrics}

Figure 4 shows the electrical resistivity of $\mathrm{CB}$ coated cotton fabric as a function of $\mathrm{CB}$ amount. From the figure, it can be seen that the electrical resistivity of coated fabrics decreased with increasing of $\mathrm{CB}$ amount. While the electrical resistivity of neat cotton fabric was $1.4 \mathrm{E}+09 \Omega \mathrm{cm}$, the addition of $0.5 \mathrm{mg} / \mathrm{ml} \mathrm{CB}$ was decreased the electrical resistivity to
$1.0 \mathrm{E}+09 \Omega \mathrm{cm}$. Furthermore, the lowest electrical resistivity was obtained at $5 \mathrm{mg} / \mathrm{ml} \mathrm{CB}$ loading as $5.8 \mathrm{E}+07 \Omega \mathrm{cm}$. At higher $\mathrm{CB}$ loads, the resistivity decreases, suggesting that CB nanoparticles act as electrically conductive bridges. This decrease in electrical resistivity can be probably due to increase in number of $\mathrm{CB}$ networks.

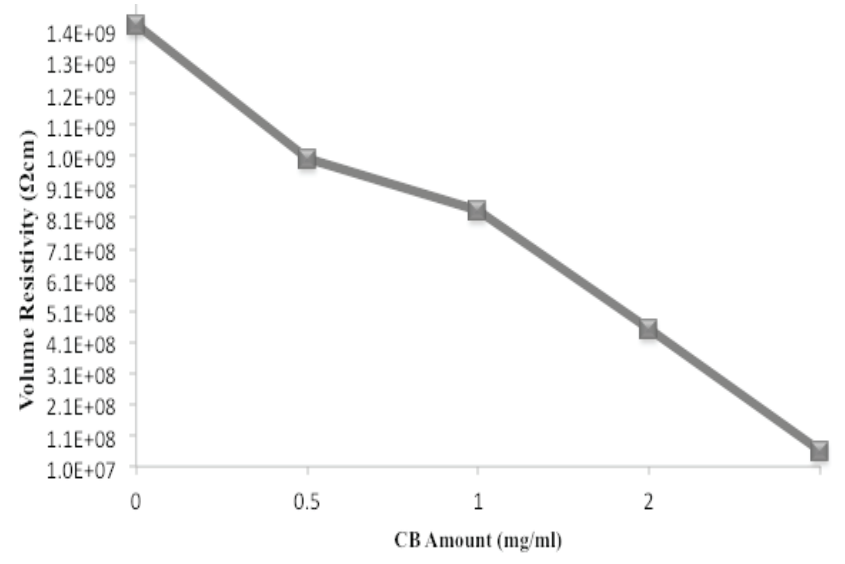

Figure 4. Electrical resistivity of $\mathrm{CB}$ coated cotton fabrics as a function of $\mathrm{CB}$ amount.

\subsection{Thermal Conductivity of Coated Fabrics}

Figure 5 shows the thermal conductivity results of $\mathrm{CB}$ coated cotton fabrics as a function of $\mathrm{CB}$ amount. From the figure, we can say that the addition of increasing amount of $\mathrm{CB}$ was increased the thermal conductivity of coated fabrics. The addition of only small amount of CB $(0.5 \mathrm{mg} / \mathrm{ml})$ to the fabric was increased the thermal conductivity from 0.107 to $0.126 \mathrm{~W} / \mathrm{mK}$. The highest thermal conductivity was obtained from $\mathrm{CB}$ coated cotton fabric at $1 \mathrm{mg} / \mathrm{ml} \mathrm{CB}$ concentration. However, further addition of $\mathrm{CB}$ affected thermal conductivity negatively, but thermal conductivities of coated fabrics were still higher than that of neat cotton fabric.

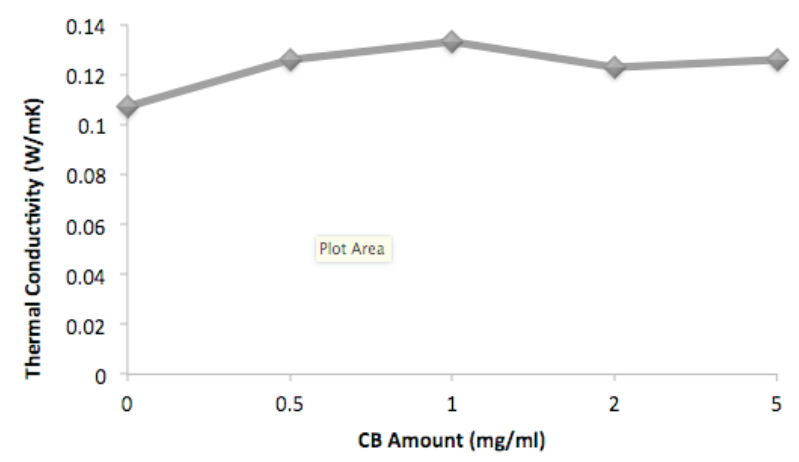

Figure 5. Thermal conductivity of $\mathrm{CB}$ coated cotton fabrics as a function of $\mathrm{CB}$ amount. 


\section{CONCLUSIONS}

In this study, the effects of carbon black loading on thermal and electrical conductivity properties of cotton fabrics were investigated. The results obtained from analysis were listed in the below.

- From the SEM images, CB nanoparticles were successfully coated on the cotton fabric surface.

- The highest fabric mass increment was obtained at 2 $\mathrm{mg} / \mathrm{ml} \mathrm{CB}$ concentration.

- The electrical resistivity decreased from $1.4 \mathrm{E}+09 \Omega \mathrm{cm}$ to $5.8 \mathrm{E}+07 \Omega \mathrm{cm}$ at $5 \mathrm{mg} / \mathrm{ml} \mathrm{CB}$ concentration.

- The thermal conductivity increased from $0.107 \mathrm{~W} / \mathrm{mK}$ to $0.133 \mathrm{~W} / \mathrm{mK}$ at $1 \mathrm{mg} / \mathrm{ml} \mathrm{CB}$ concentration.

\section{REFERENCES}

[1] Li, D. and G. Sun, Coloration of textiles with selfdispersible carbon black nanoparticles. Dyes and Pigments, 2007. 72: p. 144-149.

[2] Negru, D., C.T. Buda, and D. Avram, Electrical Conductivity of Woven Fabrics Coated with Carbon Black Particles. FIBRES \& TEXTILES in Eastern Europe, 2012. 20(1): p. 53-56.

[3] Salaeh, S. and C. Nakason, Influence of Modified Natural Rubber and Structure of Carbon Black on Properties of Natural Rubber Compounds. POLYMER COMPOSITES, 2012: p. 1-12.

[4] Iijima, M., et al., Effect of structure of cationic dispersants on stability of carbon black nanoparticles and further processability through layer-by-layer surface modificatio. Chemical Engineering Science, 2013. 85: p. 30-37.

[5] Sanchez- Gonzalez, J., et al., Electrical conductivity of carbon blacks under compression. Carbon, 2005. 43: p. 741-747.

[6] Al-Saleh, M.H. and U. Sundararaj, Nanostructured carbon black filled polypropylene/polystyrene blends containing styrene-butadiene-styrene copolymer: Influence of morphology on electrical resistivity. European Polymer Journal, 2008. 44: p. 1931-1939.

[7] Pantea, D., et al., Electrical conductivity of conductive carbon blacks: influence of surface chemistry and topology. Applied Surface Science, 2003. 217: p. 181193.

[8] Pantea, D., et al., Heat-treatment of carbon blacks obtained by pyrolysis of used tires. Effect on the surface chemistry, porosity and electrical conductivity. Journal of Analytical and Applied Pyrolysis, 2003. 67: p. 55-76.

[9] Heiser, J.A. and J.A. King, Thermally Conductive Carbon Filled Nylon 6,6. POLYMER COMPOSITES, 2004. 25(2): p. 186-193.

[10] Xiang, J. and L.T. Drzal, Investigation of exfoliated graphite nanoplatelets $(\mathrm{xGnP})$ in improving thermal conductivity of paraffin wax-based phase change material. Solar Energy Materials \& Solar Cells, 2011. 95: p. 1811-1818. 